\title{
Refractory Diffuse Large B-Cell Lymphoma Activated B-Cell Type
}

National Cancer Institute

\section{Source}

National Cancer Institute. Refractory Diffuse Large B-Cell Lymphoma Activated B-Cell

Type. NCI Thesaurus. Code C160239.

Diffuse large B-cell lymphoma activated B-cell type that is resistant to treatment. 